\title{
CULTIVO DE CANAFÍSTULA (Peltophorum dubium) EM MINIJARDIM CLONAL E PROPAGAÇÃO POR MINIESTACAS
}

\author{
CULTIVATION OF CANAFISTULA (Peltophorum dubium) IN MINI-CLONAL HEDGE AND \\ PROPAGATION BY MINI-CUTTINGS
}

Nilton Mantovani ${ }^{1}$ Marcelo Roveda ${ }^{2}$ Laura Tres $^{3}$ Fabiano de Oliveira Fortes ${ }^{4}$ Magali Ferrari Grando ${ }^{5}$

\section{RESUMO}

O objetivo deste trabalho foi avaliar o comportamento da canafístula (Peltophorum dubium Spreg. Taub.) cultivada em sistema de minijardim clonal e estudar a viabilidade da aplicação da técnica de miniestaquia para a propagação vegetativa desta espécie. Na formação das minicepas, de origem seminal, mantiveram-se diferentes números de folhas (três ou mais, uma folha ou um par de folhas). Avaliou-se a sobrevivência das minicepas, número, comprimento e diâmetro dos brotos e a produtividade média de miniestacas por minicepa durante sucessivas rebrotas. Avaliou-se ainda o efeito da aplicação do $\operatorname{AIB}\left(0 ; 1500 ; 3000 ; 4500\right.$ e $\left.6000 \mathrm{mg} \mathrm{L}^{-1}\right)$ sobre a sobrevivência e o enraizamento de miniestacas basais e apicais. A sobrevivência das minicepas foi de $100 \%$ independentemente do número remanescente de folhas na sua formação. A manutenção de 1 folha possibilitou a formação de maior número de brotos $(3,39)$ por minicepa; 1 par de folhas promoveu maior comprimento dos brotos $(12,41 \mathrm{~cm})$ e; 3 folhas ou mais originaram brotos de maior diâmetro. A produção média de miniestacas/ minicepa/coleta foi crescente ao longo das sucessivas rebrotas, com máxima produtividade (159 miniestacas $\left.\mathrm{m}^{-2}\right)$ na $4^{\mathrm{a}}$ rebrota. Miniestacas apicais apresentam maior potencial de enraizamento do que as basais. $\mathrm{O}$ AIB é dispensável na indução radicial, mas estimula a produção de massa seca das raízes. O manejo da canafístula em sistema de minijardim clonal possibilita a produção de brotos para processos de propagação clonal através da miniestaquia.

Palavras-chave: miniestaquia; propagação vegetativa; AIB.

\section{ABSTRACT}

The present work aimed to evaluate the behavior of canafistula, established in mini-clonal hedge system and the viability of applying the mini-cutting technique for vegetative propagation of this species. In the formation of mini-stumps, of seminal origin, different numbers of leaves were maintained (three or more leaves, one, or a pair of leaves). It was evaluated the survival of mini-stumps, number, length and diameter of shoots and average productivity of mini-cuttings by mini-stumps during the successive regrowth. The

1 Engenheiro Florestal, Dr., Professor Adjunto do Departamento de Engenharia Florestal, Centro de Educação Superior Norte RS, Universidade Federal de Santa Maria, Linha 7 de Setembro, s/n, BR 386 Km 40, CEP 98400000, Frederico Westphalen (RS), Brasil. mantovani.nilton@gmail.com

2 Engenheiro Florestal, MSc., Doutorando do Programa de Pós-Graduação em Engenharia Florestal, Universidade Federal do Paraná, Av. Prefeito Lothário Meissner, 900, Jardim Botânico, CEP 80210-170, Curitiba (PR), Brasil. marcelo_roveda@hotmail.com

3 Engenheira Florestal, Mestranda no Programa de Pós-graduação em Agronomia, Universidade de Passo Fundo, Campus Universitário São José, CEP 99010-970, Passo Fundo (RS), Brasil. lau_tres@yahoo.com.br

4 Engenheiro Florestal, Dr., Professor Adjunto do Departamento de Engenharia Florestal, Centro de Educação Superior Norte RS, Universidade Federal de Santa Maria, Linha 7 de Setembro, s/n, BR 386 Km 40, CEP 98400000, Frederico Westphalen (RS), Brasil. fabianofortes@gmail.com

5 Bióloga, Dr ${ }^{\mathrm{a}}$, Professora Titular da Universidade de Passo Fundo, Faculdade de Agronomia e Medicina Veterinária, Programa de Pos-Graduação em Agronomia, Campus Universitário São José, CEP 99010-970, Passo Fundo (RS), Brasil. magali@upf.br 
effect of the application of IBA $\left(0,1500,3000,4500\right.$ and $\left.6000 \mathrm{mg} \mathrm{L}^{-1}\right)$ on survival and rooting of basal and apical mini-cuttings were also evaluated. The mini-stumps survival was $100 \%$ regardless of the number of leaves remaining in its formation. The maintenance of one leaf allowed the formation of a larger number of shoots (3.39) per mini-stump, 1 pair of leaves promoted greater shoot length $(12.41 \mathrm{~cm})$, and with three or more leaves, the shoots had larger diameters. The average production of mini-cuttings/mini-stump/ harvesting has been growing over the successive regrowth, with maximum yield (159 mini-cuttings $\mathrm{m}^{2}$ ) observed on the 4th regrowth. Apical mini-cuttings show higher rooting potential than the basal. The IBA is dispensable in the radicial induction but stimulates the root dried mass. The cultivation of the canafistula in mini-clonal hedge system enables the production of shoots for clonal propagation through mini-cuttings. Keywords: mini-cuttings; vegetative propagation; IBA.

\section{INTRODUÇÃO}

A canafístula, Peltophorum dubium (Spreg) Taub. (Fabaceae, Caesalpinioideae), apresenta ampla distribuição natural no Brasil, ocorrendo desde os estados do Rio Grande do Sul, Mato Grosso do Sul, Goiás até a Bahia. No Rio Grande do Sul é componente da Floresta Estacional Decidual do Alto Uruguai, sendo característica de seu estrato superior (REITZ et al., 1988).

É uma planta de crescimento rápido, rústica, heliófita e com características de pioneira. A madeira, pesada e de resistência mecânica média, é utilizada na construção civil e por empresas moveleiras. Seu cultivo para fins comerciais é recomendado em reflorestamentos homogêneos (MARCHIORI, 2007).

A dormência das sementes é um dos principais problemas para produção de mudas de espécies florestais, especialmente de leguminosas (OLIVEIRA et al., 2003), como a canafístula. O alto grau de desidratação destas, quando colhidas de frutos maduros, provoca uma germinação lenta e irregular, gerando com isso, grande heterogeneidade no crescimento em altura, diâmetro e forma do caule das plantas em fase de viveiro (REITZ et al., 1988). Além destes fatores, a frutificação, restrita a um curto período do ano na região Sul, é mais uma restrição para a obtenção de sementes e produção de mudas via sexuada.

Quando oobjetivoéa uniformização doporte, forma do fustee decrescimentodasárvores, fundamental emplantioscomerciais, apropagaçãovegetativatorna-seumaalternativaviávelparaaproduçãodas mudasfrente à heterogeneidade provocada pela propagação sexuada. Aminiestaquia, variação da técnica de estaquia(ASSIS et al., 1992; ALFENAS et al., 2009), apresenta vantagens operacionais, técnicas, econômicas e de qualidade das mudas produzidas em relação ao modelo de estaquia convencional e, em comparação com a microestaquia, pode resultar em menores custos por não ser necessária a instalação de laboratórios de cultura de tecidos (ASSIS; MAFIA, 2007; XAVIER et al., 2013).

$\mathrm{Na}$ técnica de miniestaquia são utilizadas miniestacas retiradas de brotos formados em minicepas cultivadas em minijardins clonais, geralmente estabelecidos no interior de casas de vegetação (XAVIER et al., 2013). Esta técnica baseia-se no maior grau de juvenilidade das miniestacas obtidas de brotos em coletas sucessivas neste sistema, proporcionando, desta forma, melhores índices de enraizamento do material vegetal (ASSIS; MAFIA, 2007).

No entanto, o enraizamento adventício em propágulos vegetativos, especialmente de espécies lenhosas, mesmo no caso da miniestaquia, é influenciado por vários fatores que podem atuar isoladamente ou em conjunto. Dentre estes destacam-se aqueles relacionados ao processo de estaqueamento, como umidade, temperatura, luz e substrato e, os relacionados ao material vegetal como o potencial do genótipo para o enraizamento, a condição fisiológica e a idade da planta fornecedora dos brotos, presença de cofatores para o enraizamento no propágulo, a sua posição no broto, tamanho e tipo de propágulo em relação a sua consistência, presença de folhas e, época do ano em que o propágulo é obtido (HARTMANN et al., 2011).

$\mathrm{O}$ equilíbrio entre reguladores de crescimento endógenos tem forte influência no enraizamento adventício de estacas de espécies lenhosas. Uma das formas mais comuns de favorecer o balanço hormonal, para induzir o enraizamento adventício é a aplicação exógena de reguladores de crescimento, especialmente do grupo das auxinas, tais como o ácido indolbutírico (AIB). Esta auxina é transportada via corrente transpiratória para as folhas, ativando a síntese do ácido indolacético (AIA), uma auxina natural que transportada para a base das estacas induz a iniciação radicial (PASQUAL et al., 2001). O AIB é uma auxina altamente efetiva no estímulo ao enraizamento, o que se deve a sua menor fotossensibilidade e maior 
estabilidade química na planta, sendo pouco influenciada pelo sistema AIA-oxidase (HARTMANN et al., 2011). Tratamentos com AIB podem promover o aumento da porcentagem de propágulos que formam raízes, aceleração da iniciação radicial, aumento do número e qualidade de raízes produzidas e, aumento da uniformidade do sistema radicial (PASQUAL et al., 2001).

A viabilidade técnica da miniestaquia na propagação vegetativa em larga escala, já comprovada em nível comercial para o Eucalyptus e outros gêneros, também tem sido avaliada de forma experimental em espécies nativas como Cedrela fissilis (XAVIER et al., 2003), Ilex paraguariensis (WENDLING; SOUZA JÚNIOR, 2003.), Erythrina falcata (MORI DA CUNHA et al., 2008), Sapium glandulatum (FERREIRA et al., 2010) e também exóticas como Toona ciliata (SILVA et al., 2012) e outras. Especial atenção nestes estudos tem sido dada a aspectos como o estabelecimento das plantas no jardim clonal, a formação e o manejo das minicepas, o tipo de miniestaca e, doses e veículos de aplicação de auxinas para a indução radicial, especialmente o AIB.

Apesar dos avanços na propagação clonal obtidos nas diferentes pesquisas, é necessário estabelecer condições ótimas para cada espécie cultivada. Para a canafístula, até o momento, não foram publicados estudos relacionados ao seu cultivo em minijardim clonal bem como a aplicação da técnica de miniestaquia para sua propagação. Desta forma, este trabalho tem como objetivo avaliar o comportamento da canafístula (Peltophorum dubium (Spreg) Taub.) sob manejo em sistema de minijardim clonal e, a viabilidade da aplicação da técnica de miniestaquia para a propagação desta espécie.

\section{MATERIAIS E MÉTODOS}

Este trabalho foi desenvolvido no viveiro florestal do Departamento de Engenharia Florestal da Universidade Federal de Santa Maria (UFSM) campus de Frederico Westphalen - RS, Brasil.

\section{Implantação e manejo do minijardim clonal}

Os experimentos foram conduzidos em casa de vegetação revestida de polipropileno transparente (150 micras) sob tela de sombreamento de cor preta (50\%). No interior da casa de vegetação instalou-se o minijardim clonal constituído de canteiros suspensos, na forma de tanques em estrutura de fibra de vidro, com dimensões de $5 \mathrm{~m}$ de comprimento, $0,7 \mathrm{~m}$ de largura e $0,5 \mathrm{~m}$ de profundidade, preenchidos com seixos rolados (fragmentos de rochas basálticas com diâmetros aproximados de $60 \mathrm{~mm}$ e arestas semiarredondadas) e superficialmente com uma camada de $25 \mathrm{~cm}$ de areia de rio. A irrigação foi mantida através de um sistema composto de 4 linhas de mangueiras promovendo o gotejamento diretamente na base das minicepas (Figura 1a).

A nutrição das minicepas foi realizada a cada 30 dias através da água de irrigação com Nitrato de cálcio $\left(1,0 \mathrm{~g} \mathrm{~L}^{-1}\right)$; Cloreto de potássio $\left(0,4 \mathrm{~g} \mathrm{~L}^{-1}\right)$; Monoamônio fosfato (42 $\left.\mathrm{mg} \mathrm{L}^{-1}\right)$; Sulfato de amônio (15 $\left.\mathrm{mg} \mathrm{L}^{-1}\right)$; Sulfato de cobre $\left(0,25 \mathrm{mg} \mathrm{L}^{-1}\right)$; Sulfato de manganês $\left(2,7 \mathrm{mg} \mathrm{L}^{-1}\right)$; Molibdato de sódio $\left(0,18 \mathrm{mg} \mathrm{L}^{-1}\right)$; Sulfato de zinco $\left(0,1 \mathrm{mg} \mathrm{L}^{-1}\right)$ Hidroferro em pó $\left(83,4 \mathrm{mg} \mathrm{L}^{-1}\right)$; Ureia $\left(20 \mathrm{mg} \mathrm{L}^{-1}\right)$; Sulfato de magnésio (450 $\left.\mathrm{mg} \mathrm{L}^{-1}\right)$ e Ácido bórico $\left(2,88 \mathrm{mg} \mathrm{L}^{-1}\right)$.

As mudas de canafístula, utilizadas nos experimentos, foram produzidas em tubetes, a partir da germinação de sementes coletadas de árvores-matrizes selecionadas pelas suas características silviculturais superiores. As mudas, com seis meses de idade e $15 \mathrm{~cm}$ de altura, foram plantadas no minijardim clonal em espaçamento de $15 \mathrm{~cm}$, resultando em uma densidade de 38,6 plantas por $\mathrm{m}^{2}$.

Trinta dias após o plantio, as mudas foram podadas na altura de $10 \mathrm{~cm}$ a partir da base do caule em contato com o substrato, eliminando-se o ápice caulinar, constituindo assim as minicepas (Figura $1 \mathrm{~b}, \mathrm{c}$ ) fornecedoras de brotos para a produção de miniestacas.

\section{Comportamento da espécie sob cultivo em minijardim clonal}

O primeiro experimento foi realizado com o objetivo de avaliar a influência do número remanescente de folhas nas minicepas sobre o comportamento da espécie sob cultivo em minijardim clonal. Assim, após o estabelecimento das plantas no minijardim, efetuaram-se podas de forma a manter diferentes números 


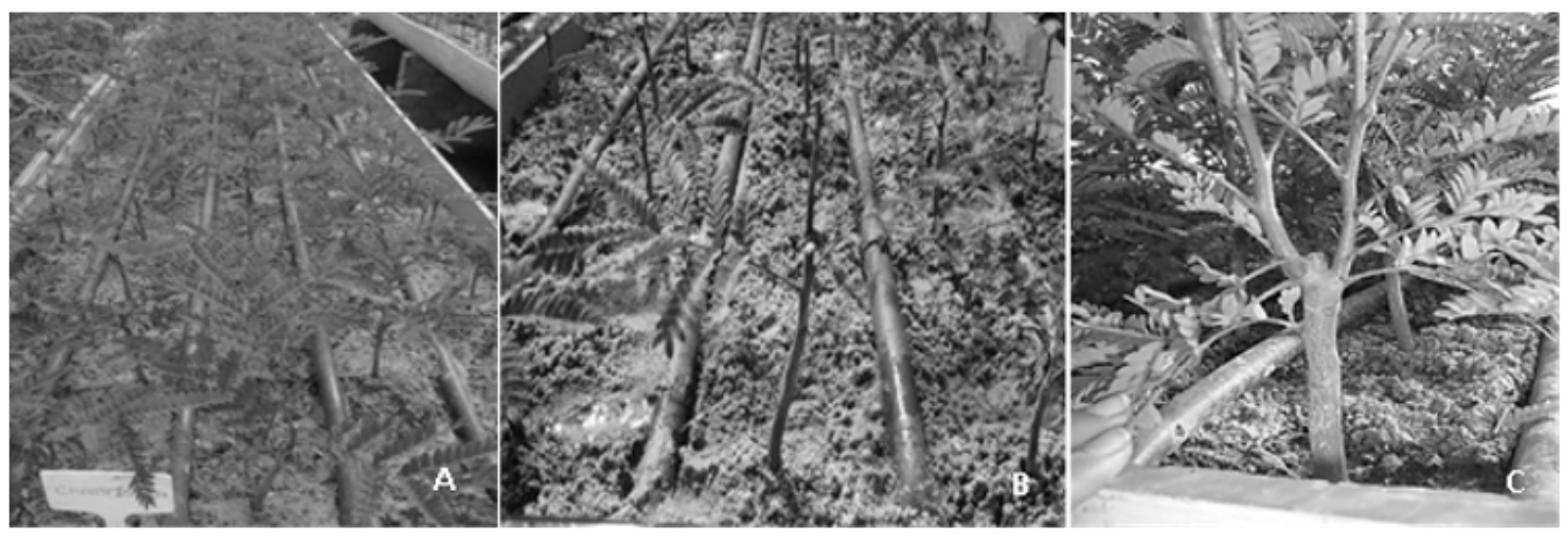

FIGURA 1: Minijardim clonal de canafístula (Peltophorum dubium). (A) Mudas estabelecidas, aos seis meses e sistema de irrigação por gotejamento; (B) Conformação das minicepas após poda do ápice e folhas; (C) Broto axilar formado em minicepa.

FIGURE 1: Mini-clonal hedge of canafistula (Peltophorum dubium). (A) Six months old seedlings and a drip irrigation system, (B) Conformation of mini-stumps after pruning the apex and leaves, (C) Axillary shoot formed in mini-stump.

de folhas nas minicepas, constituindo assim os seguintes tratamentos: T1 - (testemunha) 3 ou mais folhas remanescentes; T2 - 1 folha remanescente e T3 - um par de folhas remanescentes. As folhas foram cortadas à distância de $1,0 \mathrm{~cm}$ do caule de forma a preservar a integridade das gemas axilares e possibilitar a formação de brotos.

O experimento foi conduzido em delineamento de blocos ao acaso, com 3 tratamentos constituídos dos diferentes números de folhas remanescentes, em 5 repetições por tratamento com 10 unidades experimentais (minicepas), totalizando 150 minicepas avaliadas.

As variáveis analisadas foram: a sobrevivência de minicepas (\% de minicepas vivas) aos 49 dias depois da poda do ápice das plantas (aplicação dos tratamentos) e, aos 245 dias, após 5 rebrotas sucessivas; a velocidade de rebrota após a formação das minicepas e após cada coleta de brotos (número de dias transcorridos após a poda do ramo até a visualização de novos brotos a partir de gemas axilares); o número de brotos formados por minicepa $\left(\mathrm{N}^{\circ}\right)$ em intervalos de 7 dias, por um período de 49 dias. Para esta última variável, consideraram-se apenas aqueles brotos da posição superior das minicepas, formados acima dos 5 $\mathrm{cm}$ de altura e, com comprimento superior a $1,0 \mathrm{~cm}$. Avaliaram-se ainda o comprimento $(\mathrm{cm})$ e o diâmetro $(\mathrm{mm})$ dos brotos novos formados, o número de folhas $\left(\mathrm{N}^{\circ}\right)$ por broto e o diâmetro $(\mathrm{mm})$ do caule a $2 \mathrm{~cm}$ da base das minicepas aos 49 dias.

Durante 5 rebrotas sucessivas, em intervalos regulares de 49 dias (totalizando 245 dias), determinou-se o número médio de miniestacas $\left(\mathrm{N}^{\circ}\right)$ produzidas por minicepa e a produtividade média de miniestacas no jardim $\left(\mathrm{N}^{\circ} / \mathrm{m}^{2}\right.$ de canteiro), com comprimento da miniestaca de $5 \mathrm{~cm}$. Para estas variáveis foram consideradas somente as minicepas que permaneceram com uma folha na sua formação (T2) por ter sido observada a formação de maior número de brotos, quando comparadas às minicepas dos demais tratamentos.

\section{Enraizamento de miniestacas}

O segundo experimento foi realizado com o objetivo de avaliar a viabilidade da aplicação da técnica de miniestaquia para a propagação de canafístula. Para tanto, testaram-se dois tipos de miniestacas, com $5 \mathrm{~cm}$ de comprimento, quanto à posição de excisão no broto, apicais ou basais, e o AIB em solução hidroalcoólica (50\%), nas concentrações de 0; 1500; 3000; 4500 e, $6000 \mathrm{mg} \mathrm{L}^{-1}$.

As miniestacas permaneceram com 2 pares de folíolos e tiveram cerca de $2 \mathrm{~cm}$ de sua base imersos por 15 segundos nas diferentes soluções de AIB. Em seguida, foram estaqueadas em tubetes plásticos de 55 
$\mathrm{cm}^{3}$ contendo substrato florestal (composto de casca de pinus, fibra de coco e vermiculita em proporções iguais) e mantidas por 70 dias em casa de vegetação sob irrigação por aspersão e sombreamento de $50 \%$.

$\mathrm{O}$ experimento foi conduzido em delineamento blocos ao acaso, em arranjo fatorial $2 \times 5$, constituído dos dois tipos de estacas e das cinco concentrações de AIB, em quatro repetições compostas por 7 miniestacas. As variáveis analisadas aos 40 dias após o estaqueamento foram: a sobrevivência das miniestacas ( $\%$ de miniestacas vivas), o enraizamento (\% de miniestacas enraizadas), a formação de calos na base (\% de miniestacas contendo calos), e a massa seca do sistema radicial ( $\mathrm{mg}$ ) determinada através da secagem das raízes em estufa a $40^{\circ} \mathrm{C}$ até peso constante. Os dados de porcentagem foram transformados pela equação arco seno da raiz quadrada de $\mathrm{X} / 100$, em que $\mathrm{X}$ é o percentual da variável.

As análises estatísticas, para os dois experimentos, foram realizadas com o software SAEG (Sistema de Análises Estatísticas e Genéticas - Universidade Federal de Viçosa, RIBEIRO JÚNIOR, 2001), aplicando-se a Análise da Variância (ANOVA), comparação de médias através do teste de Tukey a 5\% de significância (para tratamentos qualitativos) e análise de regressão (para tratamentos quantitativos).

\section{Aclimatação das miniestacas enraizadas}

As miniestacas enraizadas permaneceram nos mesmos recipientes e no mesmo substrato utilizados na fase de enraizamento, sendo aclimatadas sob telado (tela de sombreamento de 30\%), com sistema de irrigação por aspersão automaticamente acionado em intervalos de 4 horas e duração de 7 minutos, por um período de 15 dias e, após, transferidas para pleno sol com o mesmo sistema de irrigação. Aos 60 dias avaliou-se a sobrevivência das plantas.

\section{RESULTADOS E DISCUSSÃO}

\section{Comportamento da espécie sob cultivo em minijardim clonal}

A sobrevivência das minicepas de canafístula cultivadas no minijardim clonal, durante o período de avaliação do experimento, foi de $100 \%$. As práticas de poda do ápice caulinar das mudas para a formação das minicepas, bem como o número remanescente de folhas ( 3 ou mais, 1 folha ou um par de folhas), mantidos após a poda, não afetaram negativamente a sobrevivência das minicepas. Da mesma forma, as coletas de brotos, realizadas em cinco rebrotas sucessivas, no período de 245 dias após o início do experimento, não prejudicaram as minicepas. Observou-se que em todas as minicepas houve aumento de diâmetro do caule, emissão de novas folhas e o desenvolvimento de brotos aproveitáveis para a produção de miniestacas. Este comportamento demonstra que o manejo adotado possibilita o cultivo da canafístula em minijardim clonal, viabilizando esta técnica para a propagação vegetativa da espécie.

Sob o aspecto da sobrevivência de minicepas submetidas a coletas sucessivas de brotos, Xavier et al. (2013) afirmam que esta depende do manejo e sistema de condução, se em tubete, canaletão ou outro tipo de estrutura. Aliado a estes, a espécie é outro fator fundamental neste aspecto, a exemplo do cedro-rosa (Cedrela fissilis) que apresentou 100\% de sobrevivência das minicepas quando cultivadas em tubetes (XAVIER et al., 2003), a corticeira-do-mato (Erythrina falcata) com 98,7\% (MORI DA CUNHA et al., 2008), a grevílea (Grevillea robusta) com 100\% de sobrevivência de minicepas (SOUZA JÚNIOR et al., 2008) e, ainda, o leiteiro (Sapium glandulatum) em que Ferreira et al. (2010) observaram 95\% de sobrevivência de minicepas durante o período de seus experimentos. Para a bracatinga (Mimosa scabrella), no entanto, o mesmo sistema de manejo adotado neste trabalho com a canafístula provocou a morte das minicepas (CASARIN et al., 2009).

A velocidade de rebrota nas minicepas não se mostrou dependente dos tratamentos. O início da formação dos brotos ocorreu em um período de sete dias depois da poda do ápice e das folhas das mudas e, no mesmo espaço de tempo depois de cada coleta de brotos em cinco rebrotas.

Houve um aumento pronunciado no número de brotos formados nas minicepas submetidas aos diferentes tratamentos, especialmente nos primeiros 14 dias (Figura 2). Para as minicepas que permaneceram inicialmente com 3 folhas ou mais (T1), o número de brotos formados por minicepa se manteve crescente até o $49^{\circ}$ dia, porém, naquelas em que foram mantidos 1 folha (T2) ou 1 par de folhas (T3), o número de 


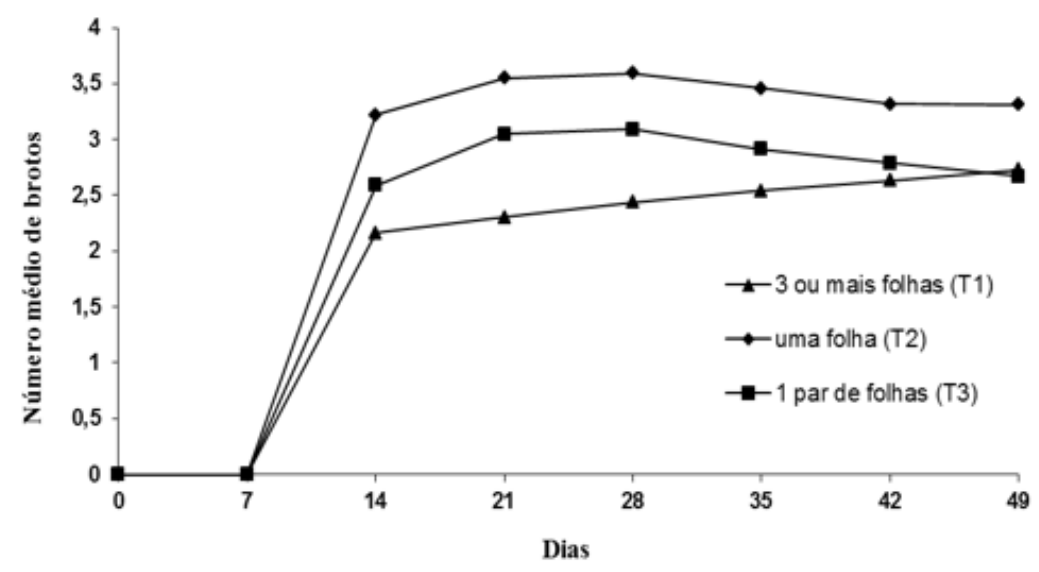

FIGURA 2: Número médio de brotos formados ao longo de 49 dias, em função do número remanescente de folhas mantido inicialmente nas minicepas de canafístula (Peltophorum dubium) em minijardim clonal.

FIGURE 2: Average number of shoots formed along 49 days, depending on the remaining number of leaves initially kept in the mini-stumps of canafistula (Peltophorum dubium) in mini-clonal hedge.

brotos foi crescente somente até o $28^{\circ}$ dia de cultivo.

Houve efeito do número remanescente de folhas nas minicepas de canafístula sobre o número total de brotos emitidos aos 49 dias (Tabela 1). Maior número de brotos $(3,40)$ foi observado nas minicepas que permaneceram com 1 folha na sua formação (T2). Os novos brotos formados nas minicepas, independentemente do tratamento, tiveram origem do crescimento de gemas axilares preexistentes.

$\mathrm{O}$ efeito do número remanescente de folhas nas minicepas de canafístula foi também verificado sobre o comprimento e o diâmetro dos brotos novos formados aos 49 dias (Tabela 1). Maiores comprimentos médios dos brotos foram observados nos tratamentos em que foi mantido 1 par de folhas (T3) e também 3 folhas ou mais (T1), os quais não diferiram entre si estatisticamente. O mesmo comportamento foi também verificado para a variável diâmetro dos brotos formados nas minicepas. Nas minicepas em que foi mantido maior número de folhas na sua formação, um par de folhas (T3) e 3 folhas ou mais (T1), ocorreu a formação de brotos de maior diâmetro. Observa-se que quanto maior o número de brotos formados nas minicepas menor seu comprimento e diâmetro. Este comportamento pode ser explicado em função da alocação de recursos como água, nutrientes e fotoassimilados presentes nas minicepas para um maior número de brotos, resultando com isso, menor comprimento e diâmetro dos mesmos.

Não houve diferença significativa para o número de folhas formadas por broto e para o diâmetro das minicepas em função dos tratamentos testados, indicando que o número de folhas mantido nas minicepas não interferiu nestas variáveis.

Houve redução do número de brotos vivos nas minicepas, em todos os tratamentos, ao longo dos 245 dias de avaliação do experimento. Em cada nova rebrota, após a coleta de brotos, apenas um ou dois brotos formados nas posições superiores das minicepas apresentavam crescimento, em detrimento dos brotos formados nas posições basais. Estes últimos, por sua vez, iniciavam o crescimento, porém, apresentavam amarelecimento e senescência foliar e morriam com poucos centímetros de comprimento. Este comportamento das brotações de canafístula ocorreu, provavelmente, em resposta a uma forte dominância apical de brotos superiores nas minicepas, inibindo o desenvolvimento dos inferiores. Esta foi uma característica marcante da espécie neste sistema de cultivo e manejo. A dominância de um broto sobre os demais foi também relata em minicepas de cedro-australiano (Toona ciliata) cultivado em minijardim clonal (SOUZA et al., 2009).

A dominância apical, também denominada de inibição correlativa, é o controle exercido pelas porções apicais dos brotos, especialmente de espécies lenhosas, sobre o crescimento das gemas axilares inferiores e de brotos superiores sobre os inferiores ao longo do eixo caulinar, estando relacionada com 
fatores endógenos nutricionais e com substâncias reguladoras do crescimento, especialmente as auxinas e citocininas e, também, ambientais, como a luz (CLINE, 1991). Segundo o mesmo autor, a poda do ápice da planta pode provocar a quebra da dominância apical por eliminar a fonte principal de auxina, modificar o gradiente desta ao longo do caule da planta, eliminar em parte o dreno de nutrientes e água, e modificar a sensibilidade dos tecidos à auxina, promovendo assim, o crescimento das gemas axilares basais. No entanto, como verificado neste trabalho com a canafístula, os brotos axilares formados nas posições superiores das minicepas passam a assumir dominância, inibindo o crescimento dos inferiores em cada rebrota.

Analisando-se a formação de brotos nas minicepas ao longo de 245 dias, em 5 rebrotas consecutivas em intervalos de 49 dias, observa-se, conforme a Tabela 2, que houve diferença significativa na produção média de miniestacas por minicepa em cada rebrota e, por consequência, na produtividade média de miniestacas por metro quadrado de canteiro no minijardim clonal. A produção de miniestacas mostrou-se crescente até a quarta rebrota, aos 196 dias, quando se obtiveram em média 4,1 miniestacas por minicepa, com a produtividade máxima de 159 miniestacas por metro quadrado de minijardim clonal. Estes resultados, no entanto, não diferem estatisticamente dos obtidos para as mesmas variáveis analisadas na terceira rebrota, revelando que, a partir desta, não houve aumento significativo no número de miniestacas e, por consequência, da produtividade por área. Este comportamento está relacionado com o próprio potencial genético de rebrota da espécie, indicando, assim, que a capacidade máxima de produção de miniestacas foi obtida na terceira e quarta rebrota. Fatores ambientais relacionadas às diferentes estações do ano nos diferentes períodos de avaliação também podem ter interferido na produção de miniestacas. A maior produtividade de miniestacas foi verificada no período entre final de inverno e início de primavera.

$\mathrm{O}$ menor número médio de miniestacas produzido pelas minicepas e por consequência menor produtividade de miniestacas por metro quadrado, observado na primeira rebrota é decorrente do processo de conformação das minicepas e adaptação ao sistema de cultivo, assim como verificado por Mori da Cunha et al. (2008) no cultivo da corticeira-do-mato (Erythrina falcata).

Resultados positivos quanto à viabilidade técnica do cultivo de espécies florestais em sistemas de minijardim clonal foram demonstrados por diferentes autores, como Wendling et al. (2007), no cultivo de erva-mate em sistema semi-hidropônico, em que se observou uma produtividade média de 291 miniestacas por metro quadrado em cada coleta, constatando aumento da produtividade de miniestacas da primeira até a quarta coleta; Mori da Cunha et al. (2008), ao cultivarem corticeira-do-mato (Erythrina falcata), obtiveram produtividade média de 2,9 miniestacas por minicepa em cada coleta utilizando sistema de canaletão e, de 1,3 em sistema de tubetes. A produção de miniestacas por minicepa em tubetes, em cada coleta, em diferentes estações do ano, para o leiteiro (Sapium glandulatum) variou de 1,4 a 2,2 (FERREIRA et al., 2010).

Os resultados obtidos neste trabalho são superiores aos encontrados para diferentes espécies florestais, indicando as potencialidades desta técnica e a sustentabilidade de produção de miniestacas de canafístula neste sistema de minijardim clonal.

\section{Enraizamento de miniestacas}

Os resultados obtidos aos 40 dias, depois do processo de estaqueamento, indicam que houve efeito isolado e interação significativa entre os fatores tipo de estaca e concentrações de AIB, para todas as variáveis analisadas no experimento. Para a percentagem de sobrevivência de miniestacas apicais e basais houve diferença significativa somente na ausência de AIB (testemunha). Nesta condição, miniestacas apicais apresentaram maior porcentagem de sobrevivência (100\%) quando comparadas às basais (60\%). Para todas as doses da auxina não houve diferença significativa para esta variável em função do tipo de miniestaca.

A aplicação do AIB, bem como o aumento nas concentrações, provocou redução na porcentagem de sobrevivência das miniestacas apicais e basais de canafístula (Figura 3). A partir do $15^{\circ}$ dia do estaqueamento, miniestacas submetidas aos tratamentos com AIB, em maior proporção nas basais e, nas concentrações maiores da auxina, apresentaram amarelecimento e senescência foliar, acompanhadas posteriormente da morte. Este fato demonstra que a auxina, nas concentrações utilizadas, provocou efeitos tóxicos nas miniestacas de canafístula. Comportamento semelhante foi observado por Bastos et al. (2004) 
TABELA 1: Efeito do número remanescente de folhas mantido em minicepas sobre o Número de Brotos formados (NB), Comprimento dos Brotos (CB), Diâmetro dos Brotos (DB), Número de Folhas por Broto (NFB) e, Diâmetro das Minicepas (DM) de canafístula (Peltophorum dubium) cultivada em minijardim clonal, aos 49 dias.

TABLE 1: Effect of the remaining number of leaves kept in mini-stumps on Number of Shoots formed (NB), Shoots Length (CB), Shoots Diameter (DB), Number of Leaves per Shoot (NFB), and Mini-stumps Diameter (DM) of canafistula (Peltophorum dubium) cultivated in mini-clonal hedge, at 49 days.

\begin{tabular}{lccccc}
\hline $\begin{array}{c}\text { Número } \\
\text { remanescente de } \\
\text { folhas nas minicepas }\end{array}$ & $\mathrm{NB}\left(\mathrm{N}^{\circ}\right)$ & $\begin{array}{c}\mathrm{CB} \\
(\mathrm{cm})\end{array}$ & $\begin{array}{c}\mathrm{DB} \\
(\mathrm{mm})\end{array}$ & $\begin{array}{c}\mathrm{NFB} \\
\left(\mathrm{N}^{\circ}\right)\end{array}$ & $\begin{array}{c}\mathrm{DM} \\
(\mathrm{mm})\end{array}$ \\
\hline $\begin{array}{l}\text { T1 - 3 ou mais } \\
\text { folhas }\end{array}$ & $2,74 \pm 0,13 \mathrm{~b}$ & $10,81 \pm 1,71 \mathrm{ab}$ & $4,91 \pm 0,31 \mathrm{a}$ & $6,64 \pm 0,37 \mathrm{a}$ & $8,35 \pm 0,39 \mathrm{a}$ \\
T2 - 1 folha & $3,40 \pm 0,19 \mathrm{a}$ & $9,48 \pm 1,27 \mathrm{~b}$ & $4,24 \pm 0,35 \mathrm{~b}$ & $6,18 \pm 0,40 \mathrm{a}$ & $7,76 \pm 0,40 \mathrm{a}$ \\
T3 - 1 par de folhas & $2,67 \pm 0,21 \mathrm{~b}$ & $12,41 \pm 1,18 \mathrm{a}$ & $5,19 \pm 0,23 \mathrm{a}$ & $6,76 \pm 0,25 \mathrm{a}$ & $8,42 \pm 0,31 \mathrm{a}$ \\
\hline
\end{tabular}

Em que : Médias \pm desvio padrão. Médias na coluna, seguidas pela mesma letra, não diferem estatisticamente entre si pelo teste de Tukey em nível de 5\% de probabilidade.

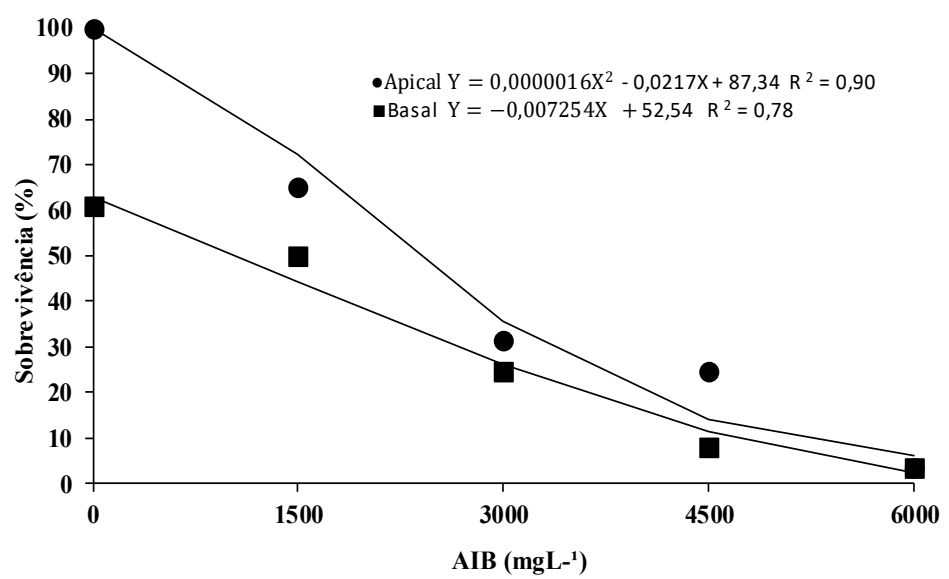

FIGURA 3: Sobrevivência (\%) de miniestacas basais e apicais de canafístula (Peltophorum dubium), tratadas com AIB nas concentrações de 0, 1500, 3000, 4500 e $6000 \mathrm{mg} \mathrm{L}^{-1}$, aos 40 dias de estaqueamento.

FIGURE 3: Average survival (\%) of basal and apical mini-cuttings of canafistula (Peltophorum dubium), treated with IBA at concentrations of $0,1500,3000,4500$ and $6000 \mathrm{mg} \mathrm{L}^{-1}$, at 40 days of staking.

e por Rezende (2007) em estudos sobre os efeitos do AIB no enraizamento de estacas de caramboleira (Averrhoa carambola) e de candeia (Eremanthus erythropapus), respectivamente.

Quanto ao enraizamento das miniestacas, observou-se que aquelas retiradas da posição apical dos ramos apresentaram maiores porcentagens de enraizamento do que aquelas retiradas da posição basal, independentemente da concentração de AIB utilizada (Figura 4). Borges (2009) realizou trabalho com Eucalyptus globulus e observou que não houve efeito do AIB no enraizamento e que miniestacas apicais apresentaram melhores resultados de enraizamento quando comparadas às intermediárias. Resultados semelhantes foram encontrados por Bastos et al. (2004) com Averrhoa carambola (goiabeira), em que estacas apicais apresentaram melhores resultados para porcentagem de sobrevivência $(49,26 \%)$ e enraizamento $(34,84 \%)$, mostrando-se superiores às basais. 
TABELA 2: Número médio de miniestacas ( $5 \mathrm{~cm}$ de comprimento) produzidas por minicepa e produtividade média de miniestacas de canafístula (Peltophorum dubium) por metro quadrado em minijardim clonal, ao longo de 5 rebrotas consecutivas (245 dias).

TABLE 2: Average number of mini-cuttings ( $5 \mathrm{~cm}$ long) produced by mini-stump and average productivity of mini-cuttings of canafistula (Peltophorum dubium) per square meter in mini-clonal hedge, over five consecutive regrowth (245 days).

\begin{tabular}{lcc}
\hline Rebrota/estação do ano & $\begin{array}{c}\text { Número médio de miniestacas }\left(\mathrm{N}^{\circ}\right) \\
\text { por minicepa }\end{array}$ & $\begin{array}{c}\text { Produtividade média de miniestacas } \\
\left(\mathrm{N}^{\circ} / \mathrm{m}^{2}\right)\end{array}$ \\
\hline 1 outono & $2,1 \pm 0,28 \mathrm{c}$ & $82,6 \pm 10,8 \mathrm{c}$ \\
2 outono/inverno & $3,2 \pm 0,42 \mathrm{~b}$ & $123,5 \pm 16,2 \mathrm{~b}$ \\
3 inverno & $4,0 \pm 0,44 \mathrm{a}$ & $157,5 \pm 17,0 \mathrm{a}$ \\
4 inverno/primavera & $4,1 \pm 0,52 \mathrm{a}$ & $159,0 \pm 20,1 \mathrm{a}$ \\
5 primavera/verão & $2,8 \pm 0,34 \mathrm{bc}$ & $106,5 \pm 13,1 \mathrm{bc}$ \\
Média & 3,2 & 125,1 \\
\hline
\end{tabular}

Em que: Médias \pm desvio padrão. Médias na coluna, seguidas pela mesma letra, não diferem estatisticamente entre si pelo teste de Tukey em nível de 5\% de probabilidade.

Em resposta à aplicação do AIB, observa-se que, quanto maior a concentração da auxina, menor o percentual de enraizamento (Figura 4). Na ausência do AIB houve maior percentual de miniestacas apicais e basais enraizadas. A maior porcentagem de enraizamento de miniestacas, observado na ausência da auxina, indica que o material vegetal apresenta um elevado potencial rizogênico natural. Condições fisiológicas adequadas para a iniciação radicial podem também ter sido induzidas pelo sistema de cultivo que favoreceu a formação de brotos rejuvenescidos e revigorados promovida pela poda do ápice das plantas e pela nutrição fornecida. Nestas condições, a aplicação de auxina exógena provoca, muitas vezes, efeitos fitotóxicos, tornando desnecessário o seu uso.

Resultados semelhantes foram também relatados por Wendling e Xavier (2005), para determinados clones de Eucalyptus grandis, por Pio et al. (2005) para oliveira (Olea europaea) e, também observados por Silva et al. (2010) no enraizamento adventício de miniestacas de guanandi (Calophyllum brasiliensis), sendo que o aumento nas concentrações da auxina foi acompanhado pelo acréscimo na mortalidade das

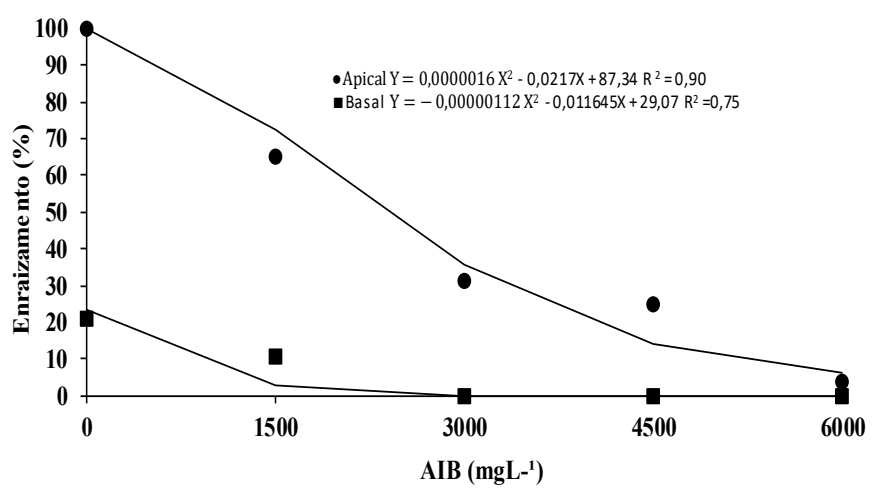

FIGURA 4: Enraizamento (\%) de miniestacas basais e apicais de canafístula (Peltophorum dubium) tratadas com AIB nas concentrações de 0, 1500, 3000, 4500 e $6000 \mathrm{mg} \mathrm{L}^{-1}$, aos 40 dias de estaqueamento.

FIGURE 4: Average rooting (\%) of basal and apical mini-cuttings of canafistula (Peltophorum dubium) treated with IBA at concentrations of $0,1500,3000,4500$ and $6000 \mathrm{mg} \mathrm{L}^{-1}$, at 40 days of staking. 
miniestacas. Para Pinus taeda (ALCANTARA, 2008), Grevillea robusta (SOUZA JÚNIOR et al, 2008) e, clones híbridos de Eucalyptus globulus (OLIVEIRA et al., 2012), a aplicação de AIB tornou-se também dispensável para o enraizamento de miniestacas.

Não foi verificada a formação de calos na base das miniestacas apicais e basais de canafístula submetidas aos tratamentos com AIB (Figuras 5 A, B, C), nem na ausência desta auxina, indicando que a calogênese nesta espécie não é pré-requisito à iniciação radicial. Embora não tenham sido realizados estudos histológicos para a identificação da origem das raízes adventícias nas miniestacas de canafístula, estudo realizado por Goulart et al (2014) revela que em miniestacas de clones de Eucalyptus grandis x Eucalyptus urophylla, a formação de primórdios radiculares e a proliferação de massas de células desorganizadas (calos) tiveram origem a partir de células presentes na região do câmbio vascular.

Quanto à produção de massa seca do sistema radicial das miniestacas de canafístula, verifica-se que miniestacas apicais (Figura $5 \mathrm{~B}$ ) apresentaram sistema radicial mais desenvolvido quando comparado ao das estacas basais (Figura 5 C), resultando, em consequência, na maior produção de massa seca.
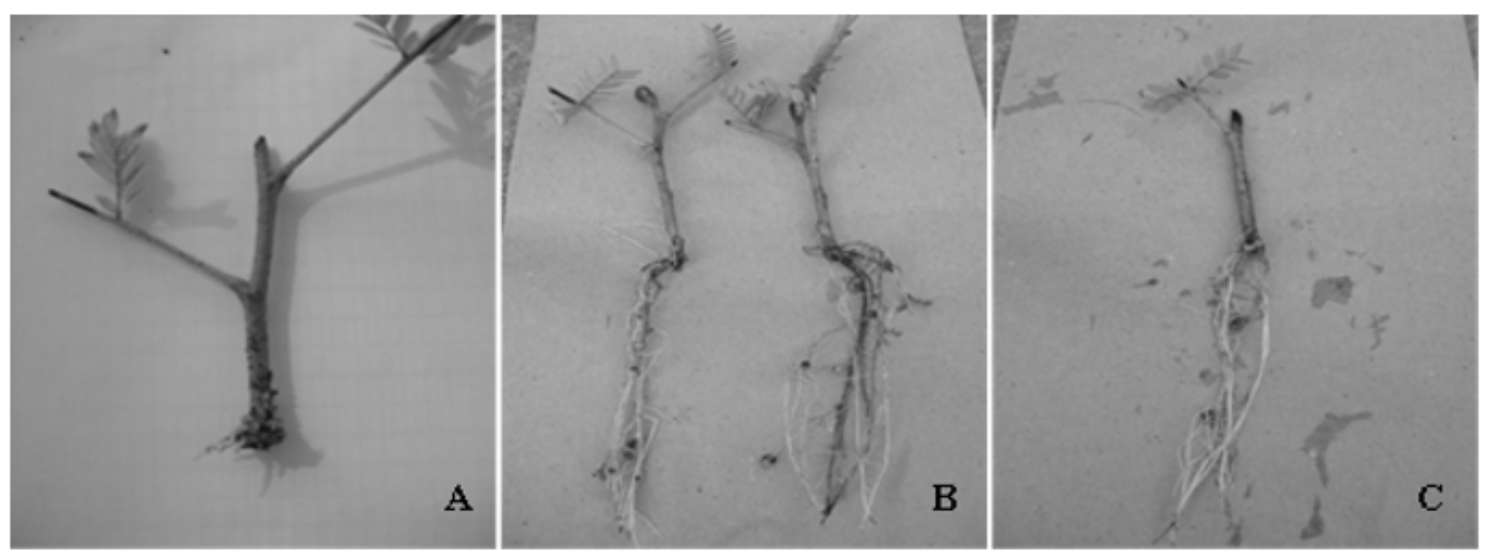

FIGURA 5: Miniestacas de canafístula (Peltophorum dubium) aos 40 dias, depois do processo de estaqueamento. (A) primórdios radiciais em miniestaca basal; (B) miniestacas apicais; (C) miniestaca basal.

FIGURE 5: Mini-cuttings of canafistula (Peltophorum dubium) at 40 days after staking process. (A) root primordia in basal mini-cutting, (B) apical mini-cuttings, (C) basal mini-cutting.

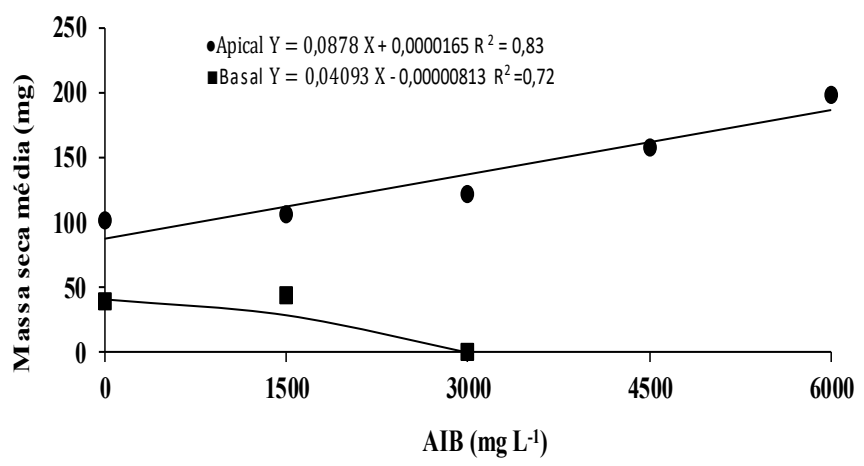

FIGURA 6: Massa seca (mg) do sistema radicial de miniestacas basais e apicais de canafístula (Peltophorum dubium) tratadas com AIB nas concentrações de 0, 1500, 3000, 4500 e $6000 \mathrm{mg}$ $\mathrm{L}^{-1}$, aos 40 dias de estaqueamento.

FIGURE 6: Root system dry mass (mg) of basal and apical mini-cuttings of canafistula (Peltophorum dubium) treated with IBA at concentrations of $0,1500,3000,4500$ and $6000 \mathrm{mg} \mathrm{L}^{-1}$, at 40 days of staking. 
Em relação ao efeito do AIB, observa-se que houve crescente incremento na produção de massa seca do sistema radicial das miniestacas apicais com o aumento nas concentrações da auxina (Figura 6).

Embora o AIB tenha provocado efeito inibitório no processo de indução radicial nas miniestacas de canafístula, esta auxina promoveu maior produção de massa seca, refletida no número, tamanho e diâmetro das raízes das miniestacas apicais, quando comparadas àquelas não tratadas com o AIB. Este comportamento foi também relatado por Sampaio et al. (2010) no enraizamento de miniestacas de preciosa (Aniba canellila), que demonstram que o AIB pode promover o aumento no número, volume e também comprimento de raízes.

As miniestacas enraizadas apresentaram $100 \%$ de sobrevivência e desenvolvimento normal durante o processo de rustificação em telado e a pleno sol.

\section{CONCLUSÕES}

Com base nos resultados obtidos neste estudo, conclui-se que o cultivo e o manejo da canafístula, em sistema de minijardim clonal, possibilitam a produção de brotos para a obtenção de miniestacas com vistas à propagação vegetativa da espécie através da técnica de miniestaquia. $\mathrm{O}$ número de folhas, mantido inicialmente nas minicepas, tem efeito significativo sobre o número, comprimento e diâmetro dos brotos formados. Miniestacas apicais são potencialmente mais responsivas ao enraizamento do que miniestacas basais. A aplicação de AIB inibe o enraizamento e diminui a sobrevivência das miniestacas, porém, proporciona incremento na massa do sistema radicial de miniestacas apicais.

\section{REFERÊNCIAS}

ALCANTARA, G. B. et al. Efeitos do ácido indolilbutírico (AIB) e da coleta de brotações em diferentes estações do ano no enraizamento de miniestacas de Pinus taeda L. Scientia Forestalis, Piracicaba, v. 36, n. 78, p. 151-156, jun. 2008.

ALFENAS, A. C. et al. Clonagem e doenças do eucalipto. 2. ed. Viçosa: Editora UFV, 2009. 500 p. ASSIS, T. F. et al. Propagação clonal de Eucalyptus por microestaquia. In: CONGRESSO FLORESTAL ESTADUAL, 7., 1992, Nova Prata. Anais... Santa Maria: UFSM, 1992. p. 824- 836.

ALFENAS, A. C.; MAFIA, R. G. Hibridação e clonagem. In: BORÉM, A. (Ed.). Biotecnologia Florestal. Viçosa: Suprema, 2007. p. 93-121.

BASTOS, D. C. et al. Influência do ácido indolbutírico no enraizamento de estacas apicais e basais de caramboleira (Averrhoa carambola) sob condições de nebulização intermitente. Revista Brasileira de Fruticultura, Jaboticabal, v. 26, n. 2, p. 284-286, ago. 2004.

BORGES, S. R. Micropropagação e enraizamento de miniestacas de clones híbridos de Eucalyptus globulus. 2009. 72 f. Dissertação (Mestrado em Ciência Florestal) - Universidade Federal de Viçosa, Viçosa, 2009.

CASARIN, C. et al. Propagação de bracatinga através de miniestacas em sistema de minijardim clonal. In: JORNADA ACADÊMICA INTEGRADA DA UNIVERSIDADE FEDERAL DE SANTA MARIA, 24., 2009, Santa Maria. Anais... Santa Maria: UFSM, 2009. Disponível em: $<$ http://w3.ufsm.br/jai/>. Acesso em: 21 abr. 2013.

CLINE, M. G. Apical Dominance. The Botanical Review, New York, v. 57, n. 4, p. 318-358, 1991.

FERREIRA, B. G. A. et al. Miniestaquia de Sapium glandulatum (Vell.) PAX com o uso de ácido indol butírico e ácido naftaleno acético. Ciência Florestal, Santa Maria, v. 20, n. 1, p. 19-31, jan./mar. 2010.

GOULART, P. B. et al. Morfoanatomia da rizogênese adventícia em miniestacas de Eucalyptus grandis x Eucalyptus urophylla. Ciência Florestal, Santa Maria, v. 24, n. 3, p. 521-532, jul./set. 2014.

HARTMANN, H. T. et al. Plant propagation: principles and practices. 8th ed. New Jersey: Prentice-Hall, 2011. $915 \mathrm{p}$.

MARCHIORI, J.N.C. Dendrologia das angiospermas: leguminosas. 2. ed. Santa Maria: Editora da UFSM, 2007. $97 \mathrm{p}$.

MORI DA CUNHA, A. C. M. C. et al. Miniestaquia em sistema de hidroponia e em tubetes de Corticeira-do-mato. Ciência Florestal, Santa Maria, v. 18, n. 1, p. 85-92, jan./mar. 2008. 
OLIVEIRA, L. M. et al. Avaliação de métodos para quebra da dormência e para a desinfestação de sementes de canafístula Peltophorum dubium (Sprengel) Taubert. Revista Árvore, Viçosa, MG, v. 27, n. 5, p. 597-603, 2003.

OLIVEIRA, L. S. et al. Enraizamento de miniestacas e microestacas de clones de Eucalyptus urophylla $\mathrm{x}$ E. globulus e de Eucalyptus grandis x E. globulus. Scientia Forestalis, Piracicaba, v. 40, n. 96, p. 507-516, dez. 2012.

PASQUAL, M. et al. Fruticultura comercial: propagação de plantas frutíferas. Lavras: UFLA/FAEPE, 2001. $137 \mathrm{p}$.

PIO, R. et al. Enraizamento de diferentes tipos de estacas de oliveira (Olea europaea 1.) utilizando ácido indolbutírico. Ciência e Agrotecnologia, Lavras, MG, v. 29, n. 3, p. 562-567, mai./jun. 2005.

REITZ, R. et al. Projeto madeira do Rio Grande do Sul. Porto Alegre: CORAG, 1988. 525 p.

REZENDE, A. A. Rooting of candeia (Eremanthus erythropapus (DC.) MacLeish) by cuttings. 2007. 75 f. Dissertation (Master in Production Forests) - Federal University of Lavras, Lavras, 2007.

RIBEIRO JÚNIOR J. I. Análises estatísticas no SAEG. Viçosa: UFV, 2001. 301 p.

SAMPAIO, P. T. B. et al. Propagação vegetativa por miniestacas de preciosa (Aniba canellila (H. B.K) MEZ). Acta Amazonica, Manaus, v. 40, p. 687-692, 2010.

SILVA, R. L. et al. Propagação clonal de guanandi (Calophyllum brasiliense) por miniestaquia. Agronomia Costarricense, San José, v. 34, n. 1, p. 99-104, 2010.

SILVA, M. P. S. et al. Enraizamento de miniestacas e produtividade de minicepas de cedro australiano manejadas em canaletões e tubetes. Ciência Florestal, Santa Maria, v. 22, n. 4, p. 703-713, out./dez. 2012. SOUZA, J. C. A. V. et al. Propagação vegetativa de cedro-australiano (Toona ciliata M. Roemer) por miniestaquia. Revista Árvore, Viçosa, MG, v. 33, n. 2, p. 205-213, 2009.

SOUZA JÚNIOR, L. et al. Miniestaquia de Grevillea robusta A. Cunn. a partir de propágulos juvenis. Ciência Florestal, Santa Maria, v. 18, n. 4, p. 455-460, out./dez. 2008.

XAVIER, A. et al. Propagação vegetativa de cedro-rosa por miniestaquia. Revista Árvore, Viçosa, MG, v. 27, n. 2, p. 139-143, 2003.

XAVIER, A. et al. Silvicultura clonal: princípios e técnicas. 2. ed. Viçosa: Editora UFV, 2013. 279 p.

WENDLING, I. et al. Produção e sobrevivência de miniestacas e minicepas de erva-mate cultivadas em sistema semi-hidropônico. Pesquisa agropecuária brasileira, Brasília, v. 42, n. 2, p. 289-292, fev. 2007.

WENDLING, I; SOUZA JÚNIOR, L. Propagação vegetativa de erva mate (Ilex paraguariensis Saint Hilaire) por miniestaquia de material juvenil. In: CONGRESSO SUL-AMERICANO DA ERVA-MATE, 3.; FEIRA DO AGRONEGÓCIO DA ERVA-MATE, 2003, Chapecó. Anais... Chapecó: Epagri, 2003. 1 CD-ROM.

WENDLING, I; XAVIER, A. Influência do ácido indolbutírico e da miniestaquia seriada no enraizamento e vigor de miniestacas de clones de Eucalyptus grandis. Revista Árvore, Viçosa, MG, v. 29, n. 6, p. 921-930, 2005. 